\title{
Investigation of core data reliability to support time-lapse interpretation in Campos Basin,
}

\section{Brazil}

\author{
Marcos Hexsel Grochau ${ }^{1}$ and Boris Gurevich ${ }^{2}$ \\ ${ }^{1}$ Curtin University of Technology, Department of Exploration Geophysics, GPO Box U1987, Perth, Western \\ Australia 6845 and PETROBRAS - Petroleo Brasileiro S.A, Rio de Janeiro, Brazil \\ E-mail: m.grochau@postgrad.curtin.edu.au \\ ${ }^{2}$ Curtin University of Technology, Department of Exploration Geophysics, GPO Box U1987, Perth, Western \\ Australia 6845 and CSIRO Division of Petroleum Resources, ARRC, 26 Dick Perry Avenue, Kensington, Perth, \\ Western Australia 6151 \\ Email: B.Gurevich@curtin.edu.au
}

\begin{abstract}
In order to calibrate time-lapse quantitative interpretation, it is crucial to analyze saturation and pressure effects on seismic velocities. While the former is adequately modeled using Gassmann equations, the latter is mainly obtained by laboratory measurements, which can be affected by core damage. We investigate the magnitude of this effect on compressional wave velocities by comparing laboratory experiments and log measurements. We use Gassmann fluid substitution to obtain low-frequency saturated velocities from dry core measurements (thus mitigating the dispersion effects) taken at reservoir pressure. The analysis is performed for an unusual densely cored well from which 43 cores were extracted over a 45 meters thick turbidite reservoir. Comparison of these computed velocities with the sonic log measurements shows very good agreement. This confirms that for this particular region the effect of core damage on
\end{abstract}


ultrasonic measurements is below the measurement error. Consequently stress sensitivity of elastic properties as obtained from ultrasonic measurements is adequate for quantitative interpretation of time-lapse seismic data in this area.

\section{INTRODUCTION}

Analysis of pressure changes from time-lapse seismic data requires the knowledge of the effect of pressure on elastic properties of rocks. This effect is usually studied by ultrasonic measurements on core samples at different pressures. However, cores maybe irreversibly damaged during the drilling and extraction processes, inducing the creation of cracks and consequently increasing stress sensitivity. Therefore laboratory measurements, mainly pressure effect on seismic velocities, may not be representative of the in situ formation and could cause misinterpretation of time-lapse effects.

Several studies have been done to investigate core damage as a result of the stress-release during the drill-out. Holt et al. (2000) using synthetic rocks manufactured under stress, measured material properties in "virgin" conditions and compared these to properties of cores that have been unloaded to simulate coring and subsequently reloaded to in situ conditions. Nes et al. (2002) used synthetic sandstones formed under stress to perform a systematic study of stressrelease inducing core-damage effects.

In order to assess the adequacy of the core sample measurements to the properties of the intact reservoir rocks, it is necessary to compare them to in situ measurements. The most reliable in situ measurements of elastic properties of rocks are provided by the sonic log. The aim of this paper is to assess the adequacy of ultrasonic measurements on core samples by comparing 
measured ultrasonic velocities at reservoir pressures with sonic log data from a well in an oil field in Campos Basin, offshore Brazil.

The well was chosen because of an unusually large number of core sample measurements: 43 samples of sandstone were available from 45 meters of the turbidite reservoir, providing a relatively good representation of reservoir properties. The under-representation is further mitigated by applying a correction for porosity mismatch between log and core measurements.

In order to mitigate the effect of dispersion we use only dry measurements (as in dry rock the dispersion is usually small). Gassmann equation is then applied to compute the properties of the saturated samples (Mavko et al., 1998), which is expected to give the static limit of the elastic properties. By using dry measurements we avoid the errors associated with the dispersion between sonic and ultrasonic frequencies which can be large for fluid-saturated samples. Still, the difference may occur due to dispersion between low-frequency (Gassmann) velocities and sonic log velocities measured at kilohertz frequency range.

By mitigating the effects of under-representation and dispersion we can focus on the effect of core damage. To assess the magnitude of this effect, we compare the saturated low frequency elastic wave velocities at reservoir conditions (computed from the laboratory measurements) with sonic log data recorded in the well.

\section{DESCRIPTION OF FIELD DATA}

The well logs and cores analyzed were obtained in the south portion of Campos Basin, around $100 \mathrm{~km}$ off the coast of Rio de Janeiro (southeastern Brazil), in a water depth of approximately 700 meters. In this basin there are more than 40 oil fields from different ages 
(Figure 1) representing a mosaic of reservoir properties. Each field and each reservoir has its own characteristics in terms of lithology, grain size, and cementation. In deep and ultra-deep water projects, it is important to avoid costly workovers; therefore programs of pressure maintenance are frequently used (Bruhn et al., 2003). Close to the water injector wells pore pressure can significantly increase, whereas in other positions it could decrease due to depletion, resulting in higher effective pressure. Considering the vast range of reservoir properties and the lateral variation of effective pressure within the reservoir, local and specific petrophysical studies should be done to guide 4D interpretations.

The reservoir is comprised of gravel to sand rich lobes from confined turbidities related to a Cretaceos Period (Santonian / Campanian) marine transgressive megasequence. This 45 meters reservoir is comprised by the amalgamation of 6 turbidites events with thickness from 2.5 to 14.5 meters each and grains size from sand conglomerate in the base to medium / coarse sandstone in to the top (Figure 2). Figure 3 shows a representative thin section of the reservoir rock which can be classified as arkosic sandstone.

After the discovery in 1984, oil production started in 1985 and the reservoir has been depleted by natural water aquifer and water injection. There are 25 wells producing 29 API oil, permeability is $1500 \mathrm{mD}$ and temperature is $89^{\circ} \mathrm{C}$. The current and forecast recovery factors are 38 and 55\%, respectively, and reservoir monitoring is important to locate unswept areas. The reservoir pressure (pore pressure) was initially close to $25.51 \mathrm{MPa}$ (3700 psi) and the average oil saturation in the interval under investigation is $90 \%$. 


\section{METHODOLOGY}

The main objective of this study is to test the adequacy of using ultrasonic measurements on core samples for quantitative interpretation of time-lapse seismic data. This strategy can be distorted by the following factors:

- Under-representation: Core samples are small and core extraction is usually extremely sparse compared to the volume of rock sampled by seismic waves. Furthermore, cores are more easily taken from well consolidated intervals, while more friable samples fall apart. Thus core samples may not be representative of the entire formation interval.

- Dispersion: Core measurements are usually performed at ultrasonic frequencies (0.25-1 MHz) and may not be representative of the properties at seismic frequencies $(10-100 \mathrm{~Hz})$ due to dispersion (variation of elastic wave velocity with frequency).

- Core damage: Cores may be irreversibly damaged during the drilling and extraction processes. Specifically, these processes can induce the creation of cracks which will increase the stress sensitivity of the cores as compared to the intact formation (Holt et al., 2000, 2005).

The proposed methodology to assess the adequacy of ultrasonic measurements to the properties of the intact rock, and test the significance of these distorting factors, consists on the following steps:

1. Extract as many cores as possible along the reservoir interval;

2. Perform dry ultrasonic measurements on these cores obtaining relation of stress sensitivity on velocities;

3. Estimate effective pressure at the reservoir level, taken into account pore pressure and 
overburden pressure;

4. Estimate rock and fluid properties existent into the reservoir interval;

5. Apply Gassmann equations to compute saturated velocities from the dry ultrasonic measurements at the reservoir effective pressure;

6. Quality control to discard some samples where the changes in rock properties could not be sampled adequately by both logs and cores (resolution problems);

7. Compare the obtained saturated velocities with log sonic measurements.

Key elements of our approach are discussed below.

\section{Logs and core measurements}

Gamma ray, saturation, sonic (velocity), porosity and density logs were used to characterize the reservoir zone (Figure 4).

Cores were extracted continuously from 49.5 meters of rocks in and close to the reservoir zone. Core measurements were obtained positioning samples between two pairs of piezoelectric transducers (for $\mathrm{P}$ and S-waves), and all together were immersed in a pressure chamber with hydraulic oil (Figure 5).

The effective pressure was increased up to $41.37 \mathrm{MPa}$ (6000 psi) with steps of $3.45 \mathrm{MPa}$ (500 psi) from 3.45 MPa up to $20.68 \mathrm{MPa}$ (3000 psi), then with steps of 6.89 MPa (1000 psi).

A sinusoidal pulse with $500 \mathrm{KHz}$ was propagated through and for each step of pressure increment velocities were determined from the travel time and the length of each sample (courtesy of J.E. Lira, A. Sobrinho and J. Pinheiro, Petrobras). 


\section{Reservoir's effective pressure estimation}

To estimate the effective pressure $\left(P_{\text {effec }}\right)$ at the reservoir we used the following equation:

$$
P_{\text {effec }}=P_{\text {over }}-P_{\text {por }} \text {, }
$$

where $P_{\text {por }}$ is the pore pressure and $P_{\text {over }}$ is the overburden pressure calculated as

$$
P_{\text {over }}=A h_{w}+B\left(h_{r}-h_{w}\right)
$$

where $A$ and $B$ are ocean water and lithostatic pressure gradients; $h_{w}$ and $h_{r}$ are water and reservoir depths, respectively.

Pore pressure was obtained from well (RFT) measurements which were made at the time when logs were acquired, and provided constant values over the reservoir interval. The resulting value of effective pressure was 34.47 MPa (5000 psi) for the interval under investigation.

\section{Calculation of elastic modulus}

Once the laboratory measurements were made on dry cores, the saturated bulk modulus $K_{\text {sat }}$ was computed using Gassmann equation:

$$
K_{s a t}=K_{d r y}+\frac{\left(1-\frac{K_{d r y}}{K_{\min }}\right)^{2}}{\frac{\phi}{K_{\text {fluid }}}+\frac{1-\phi}{K_{\min }}-\frac{K_{d r y}}{\left(K_{\min }\right)^{2}}},
$$

where

$$
K_{d r y}=\rho_{d r y}\left(V_{P d r y}^{2}-4 V_{S d r y}^{2} / 3\right)
$$

is the bulk modulus of the dry rock, $K_{\min }$ is effective modulus of the solid grains, $K_{\text {fluid }}$ is effective modulus of the saturating fluid, $V_{P d r y}$ and $V_{\text {Sdry }}$ are the compressional and shear wave 
velocities measured in dry sample, $\phi$ is the porosity and $\rho_{d r y}$ is the density of the dry sample.

As a saturation log was available, it was taken into account to calculate the fluid bulk modulus using Wood equation:

$$
\frac{1}{K_{\text {fluid }}}=\frac{1-S_{w}}{K_{o}}+\frac{S_{w}}{K_{w}},
$$

where $S_{w}$ is water saturation, $K_{o}$ and $K_{w}$ are the bulk moduli of the oil and water phases.

Finally, the saturated compressional velocity $V_{\text {Psat }}$ was obtained using the standard equation

$$
V_{P s a t}=\left(\frac{K_{s a t}+\frac{4}{3} G}{\rho_{\text {sat }}}\right)^{1 / 2},
$$

where $G=V_{S}^{2} \rho_{d r y}$ is the shear modulus of the rock, $\rho_{\text {fluid }}=S_{w} \rho_{w}+S_{o} \rho_{o}$ is the composite fluid density and $\rho_{\text {sat }}=\rho_{\text {fluid }} \phi+\rho_{\text {dry }}$ the density of the saturated rock.

According to Mavko (1995) and Winkler (1986), the dry rocks generally have little or no velocity dispersion, at least relative to the large dispersion that occurs when pore liquids are introduced. Therefore the velocities computed from dry measurements using Gassmann equations can approximately be considered as measured in the low frequency (quasi-static) limit.

As a result of this calculation, elastic moduli and saturated velocities were obtained for 43 samples for each effective pressure step (3.45 MPa to $41.37 \mathrm{MPa}$ ). As an example, Figure 6 shows the dependency of velocities on effective pressure for 6 samples. To compare with log measurements, we selected velocities corresponding to the estimated effective pressure present in situ (34.47 MPa). 


\section{Quality control and selection of subset}

Considering the large number of cores available, it was possible to discard some samples deemed to be non-representative of the reservoir properties. As can be seen in Figure 7, the reservoir interval contains a few low-porosity zones which are related to the presence of concretions containing large amounts of calcite cement either as small balls or levels. These concretions usually form very thin layers which are under-sampled (smoothed over) by both porosity and sonic logs. At the same time, core samples can be taken both from concretions and from surrounding reservoir rock. In both cases this may result in large discrepancy between log and core porosities.

Therefore the porosity criterion was primarily used to discard the samples where the difference between the porosity measurement in cores and the neutron porosity log was greater than 3\%. Figure 7 shows both measurements of porosity as well as the discarded samples (in gray). We also removed a few samples around these heterogeneous zones, even where porosity match was good, as porosity and sonic logs may have different vertical resolution and/or penetration depth.

From the original dataset of 43 we retain 27 samples which were considered representative of the reservoir sandstone and potentially comparable with log measurements.

\section{RESULTS}

Figures 8 and 9 show the comparison of the saturated velocities computed for the selected subset from cores (blue dots) against corresponding sonic log data. We see a very good agreement between the two sets of data. The average difference (systematic error) between the 
two sets is $-32 \mathrm{~m} / \mathrm{s}(0.93 \%)$, which is within the core measurement error range (up to $3 \%)$. The root mean square of the differences between sonic log and the computed core velocities is 110 $\mathrm{m} / \mathrm{s}$.

One may notice that the higher (on average) core velocities correspond to lower (on average) core porosities, compared to the log data. In other words, the cores do not fully represent the average properties of the formations as measured in logs. To reduce this effect, in Figure 10 we plot the velocity against porosity for our reservoir interval, construct a linear regression $V_{P t}(\phi)$ and apply the correction to the core velocities:

$$
\begin{array}{r}
V_{P c o r}=V_{P s a t}+\Delta V_{P}, \\
\Delta V_{P}=V_{P t}\left(\phi_{\text {log }}\right)-V_{P t}\left(\phi_{\text {lab }}\right) .
\end{array}
$$

The resulting corrected velocities are shown as red diamonds in Figure 11. After this correction, the resulting systematic difference between sonic log and the computed core velocities reduces from $-32 \mathrm{~m} / \mathrm{s}$ to $25 \mathrm{~m} / \mathrm{s}$. Effectively, this procedure corrects for the effect of underrepresentativeness of core samples. We see that either with or without correction for porosity discrepancy, the sonic and core velocities are quite close (Figures 11 and 12).

\section{CONCLUSIONS}

We have described a methodology to assess the adequacy of ultrasonic velocities measured in the laboratory for use in sonic and seismic modeling (with view to use in time-lapse interpretation), focusing on the effect of core damage.

Dispersion effects are minimized by using dry cores and then computing saturated 
velocities (Gassmann); under-representativeness of cores is reduced by extracting many cores over the reservoir interval and by applying porosity correction.

The main conclusion is that the saturated velocities computed from core measurements on dry samples match the sonic log velocities quite well. This means that the effect of core damage on the elastic properties of the core samples is small, that is, below the measurement errors. Consequently, stress sensitivity of elastic parameters as obtained from ultrasonic measurements is adequate for quantitative interpretation of time-lapse seismic data. The results also suggest the usefulness of laboratory measurements on cores, including the core preservation during extraction.

The results of the study relate to a particular reservoir in the Campos Basin offshore Brazil. Similar result was observed in Schiehallion Field by Meadows et al. (2005). Other studies in the same basin and other parts of the world are needed to verify how general this conclusion is.

\section{Acknowledgments}

The authors would like to thank Petrobras for the provision of log and core data, permission to publish this paper, and for funding PhD scholarship of Marcos Grochau. We are also grateful to David Lumley, David Dewhurst, Guilherme Vasquez and Silvia Malagutti for their ideas, opinions and comments. 


\section{References}

Bruhn, C. H. L., C. Del Luchesse, J. A. T. Gomes, and P. R. S. Johann, 2003, Campos Basin: reservoir characterization and management - historical overview and future challenges: Offshore Technology Conference, OTC 15220, Expanded Abstracts, 1 - 14.

Holt, R. M., M. Brignoli, and C. J. Kenter, 2000, Core quality: quantification of coring-induced rock alteration: International Journal of Rock Mechanics and Mining Sciences, 37, 889907.

Holt, R. M., O. M. Nes, and E. Fjaer, 2005, In-situ stress dependence of wave velocities in reservoir and overburden rocks: The Leading Edge, 24, 1268-1274.

Mavko, G. and T. Mukerji, 1995, Seismic pore space compressibility and Gassmann’s relation: Geophysics, 60, 1743-1749.

Mavko, G., T. Mukerji and J. Dvorkin, 1998, The rock physics handbook: tools for seismic analysis of porous media: Cambridge University Press.

Meadows, M., D. Adams, R. Wright, A. Tura, S. Cole and D. Lumley, 2005, Rock physics analysis for time-lapse seismic at Schiehallion Field, North Sea: Geophysical Prospecting, 53, 205-213.

Nes, O. M., R. M. Holt, and E. Fjaer, 2002, The reliability of core data as input to seismic reservoir monitoring studies: Annual International Meeting, SPE 76641, Expanded Abstracts, 79-86.

Winkler, K. W., 1986, Estimates of velocity dispersion between seismic and ultrasonic frequencies: Geophysics, 51, 183-189. 


\section{$\underline{\text { List of figure captions }}$}

Figure 1. Map of the Campos Basin oilfields showing the location and age of the main reservoirs (Bruhn et al., 2003).

Figure 2. Coarse sandstone representative of confined turbidities present in this field in Campos Basin.

Figure 3. Thin representative image from the analyzed reservoir showing mineralogical composition (quartz 39.5\%; feldspar 25.5\%; rock fragments 10.5\%; other minerals (biotite/granade) $1.5 \%$; cement $0.5 \%$; and porosity $22.5 \%$.

Figure 4. Gamma ray, water saturation, P-wave velocity, porosity and density from the studied well.

Figure 5. Measurement system device (courtesy of Vasquez, G.F., I.A. Simoes Filho, C.H.L.Bruhn and L.D. Dillon, Petrobras).

Figure 6. Velocity versus effective pressure for a selection of core samples at different depths.

Figure 7. Porosity from log versus porosity from cores showing the discarded samples (in gray) based mainly on the porosity criteria.

Figure 8. Comparison of saturated P wave velocities computed using Gassmann equation from dry core measurements (dots) against sonic log (line).

Figure 9. Differences between saturated P wave velocities computed using Gassmann equation from dry core measurements and sonic log. We can see that differences are predominantly smaller than $200 \mathrm{~m} / \mathrm{s}$.

Figure 10. Relationship between porosity and saturated P-wave velocities computed using Gassmann equations. 
Figure 11. Comparison of saturated P wave velocities computed using Gassmann equation from dry core measurements before (blue dots) and after (red diamonds) porosity correction against sonic log (line). We can see that scale effect correction slightly improves the similarity with log.

Figure 12. Differences between saturated P wave velocities computed using Gassmann equation from dry core measurements before (blue) and after (red) scale effect correction .and sonic log. We can see that both differences are predominantly smaller than $200 \mathrm{~m} / \mathrm{s}$. 


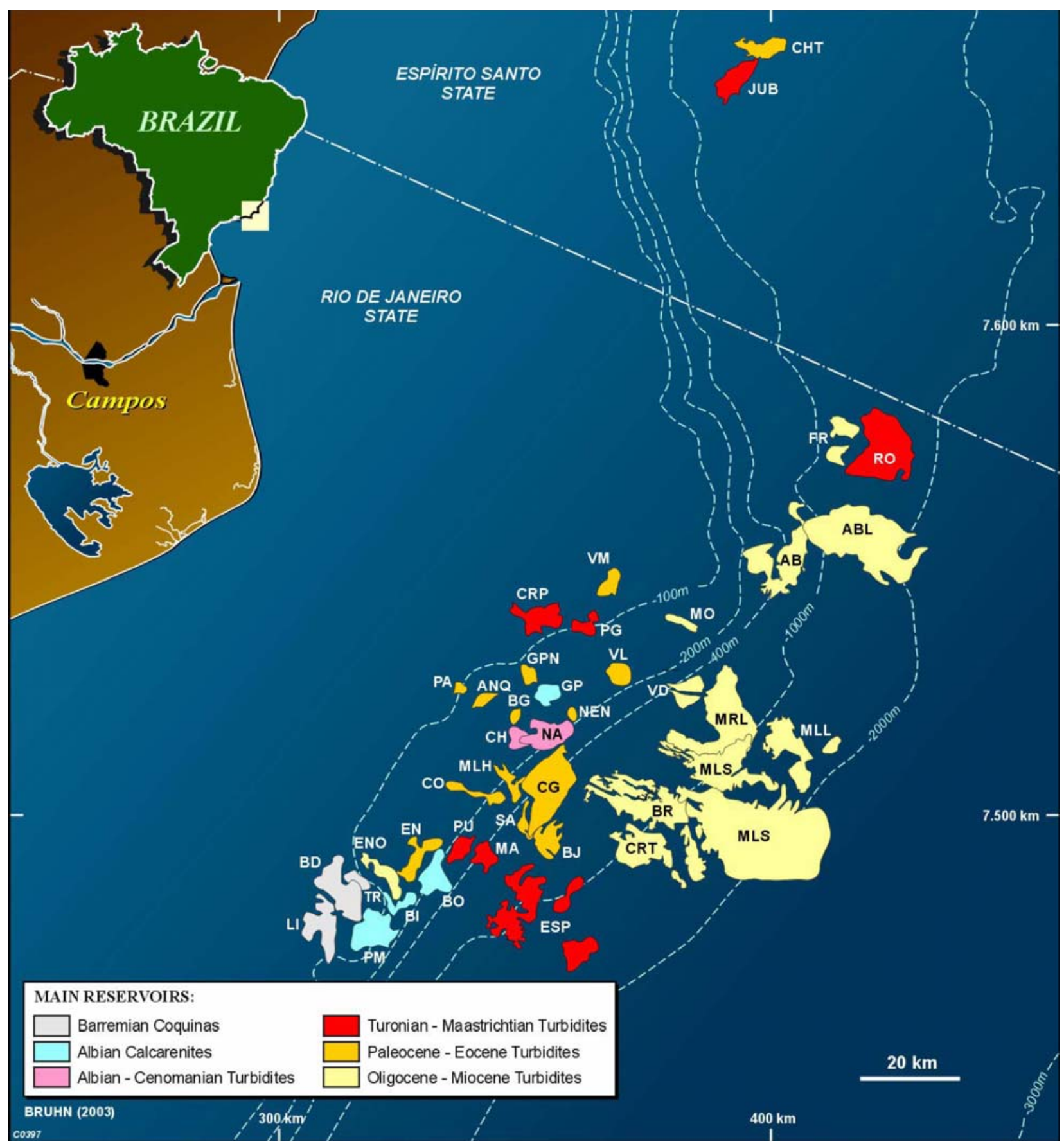

Figure 1. Map of the Campos Basin oilfields showing the location and age of the main reservoirs (Bruhn et al., 2003). 


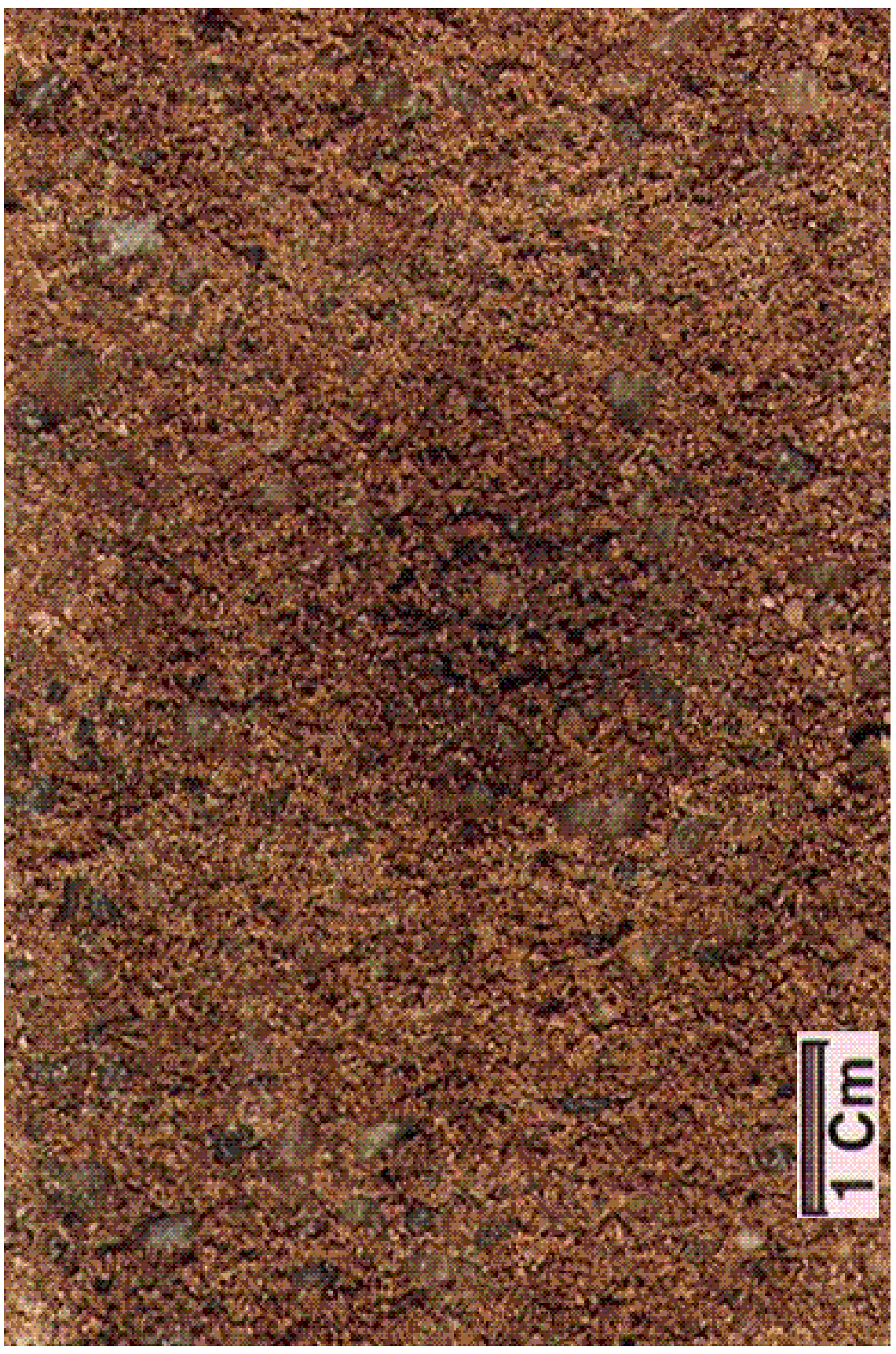

Figure 2. Coarse sandstone representative of confined turbidities present in this field in Campos Basin. 


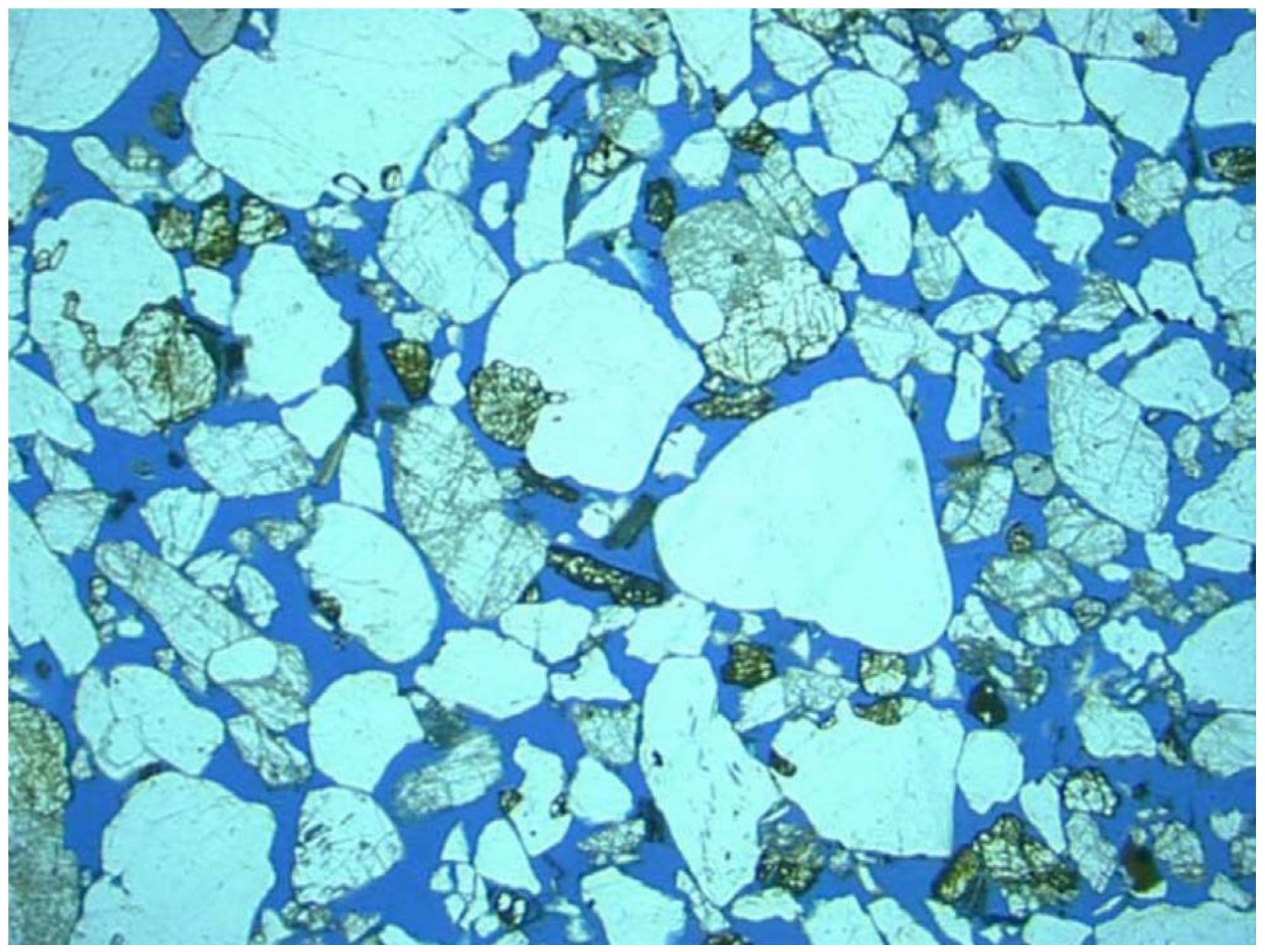

Figure 3. Thin representative image from the analyzed reservoir showing mineralogical composition (quartz 39.5\%; feldspar 25.5\%; rock fragments 10.5\%; other minerals (biotite/granade) 1.5\%; cement 0.5\%; and porosity $22.5 \%$. 


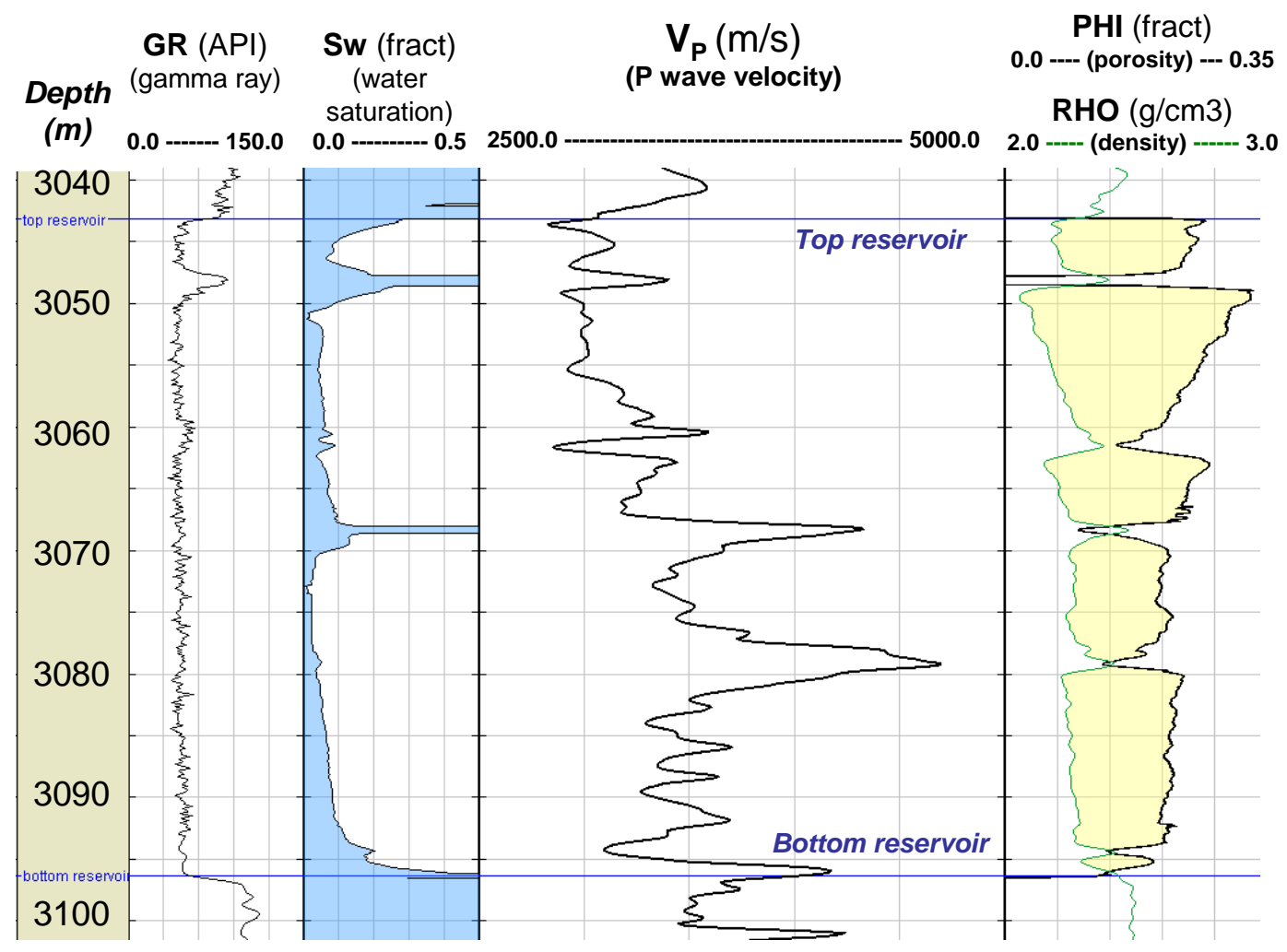

Figure 4. Gamma ray, water saturation, P-wave velocity, porosity and density logs from the studied well. 


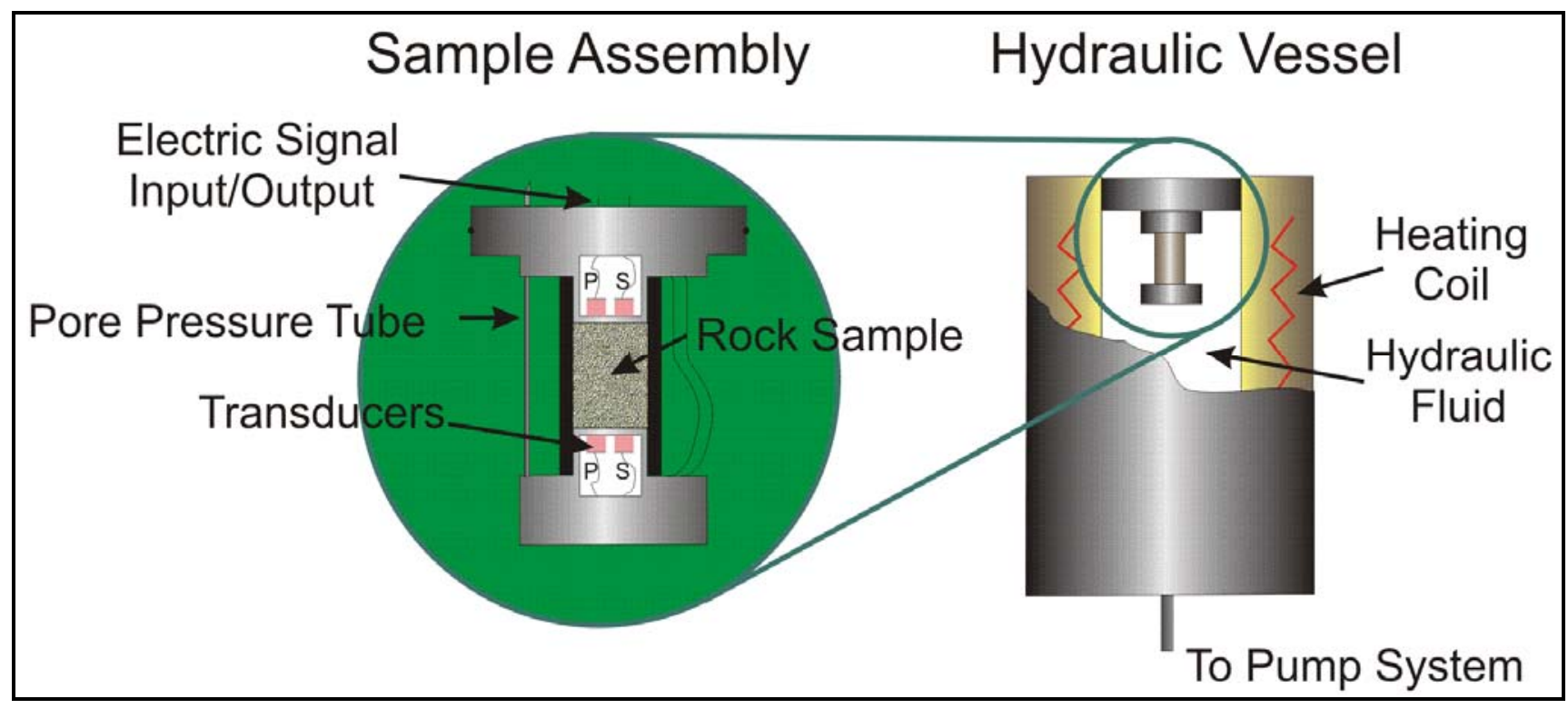

Figure 5. Measurement system device (courtesy of Vasquez, G.F., I.A. Simoes Filho, C.H.L.Bruhn and L.D. Dillon, Petrobras). 


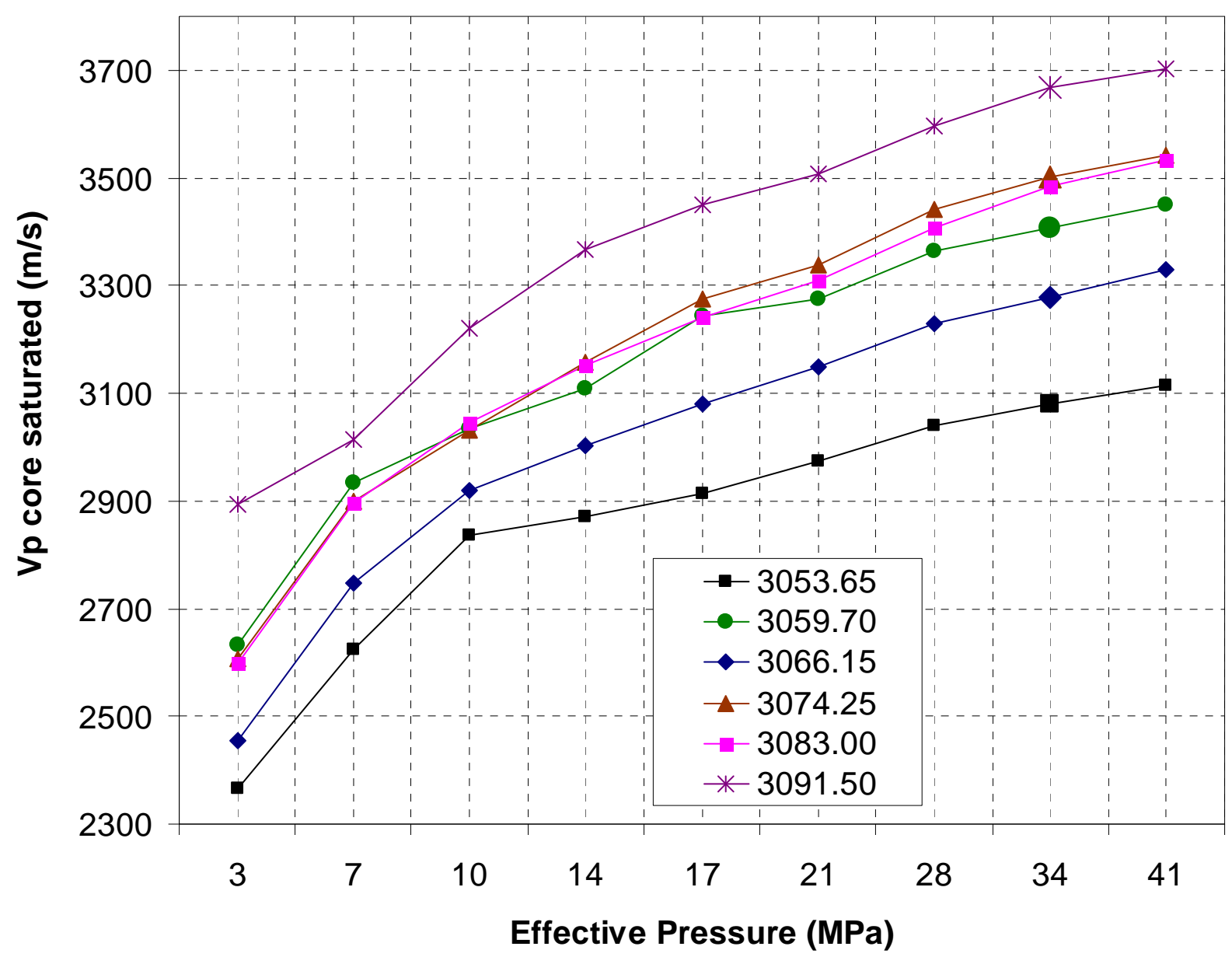

Figure 6. Velocity versus effective pressure for a selection of core samples at different depths. 


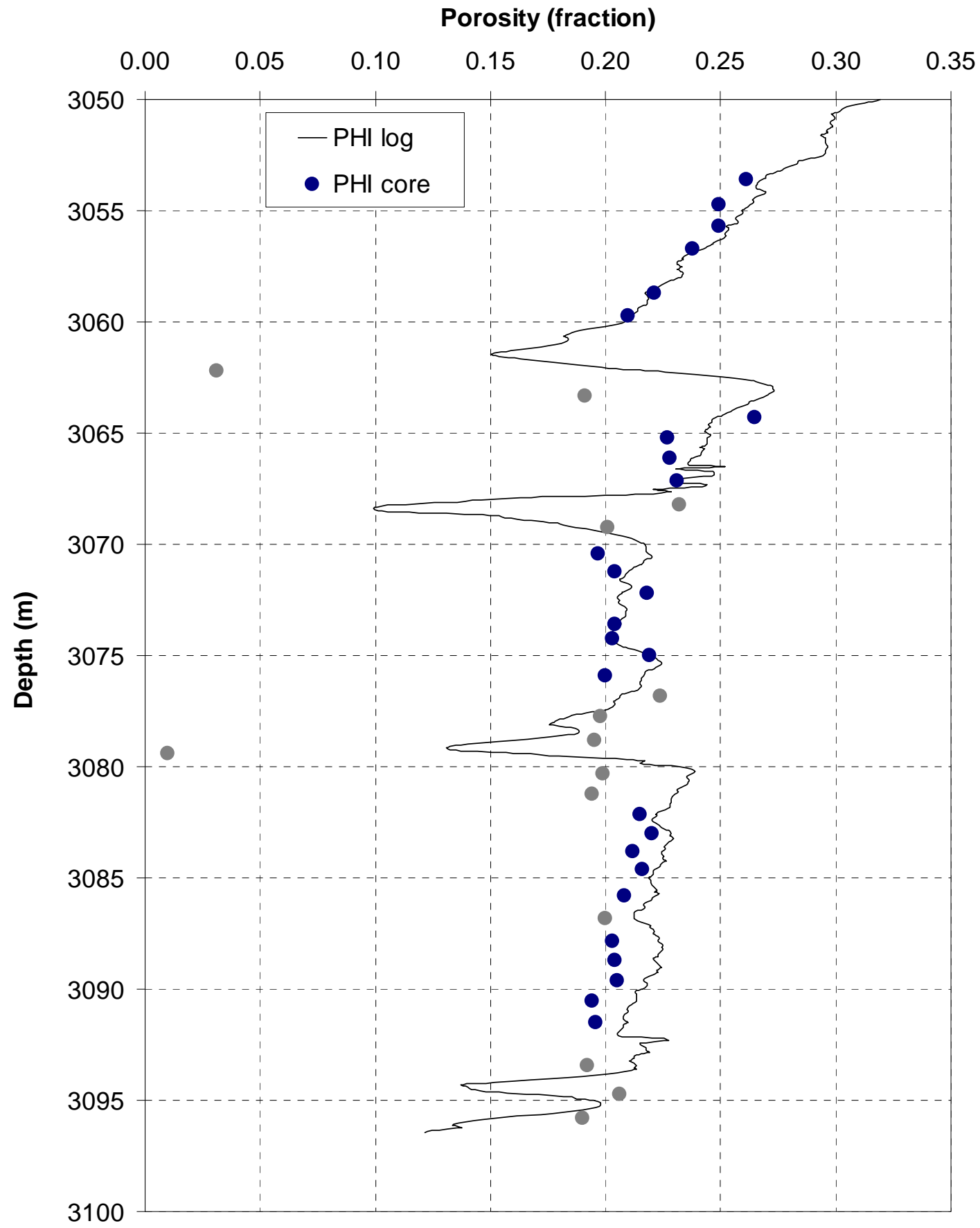

Figure 7. Porosity from log versus porosity from cores showing the discarded samples (in gray) based mainly on the porosity criteria. 


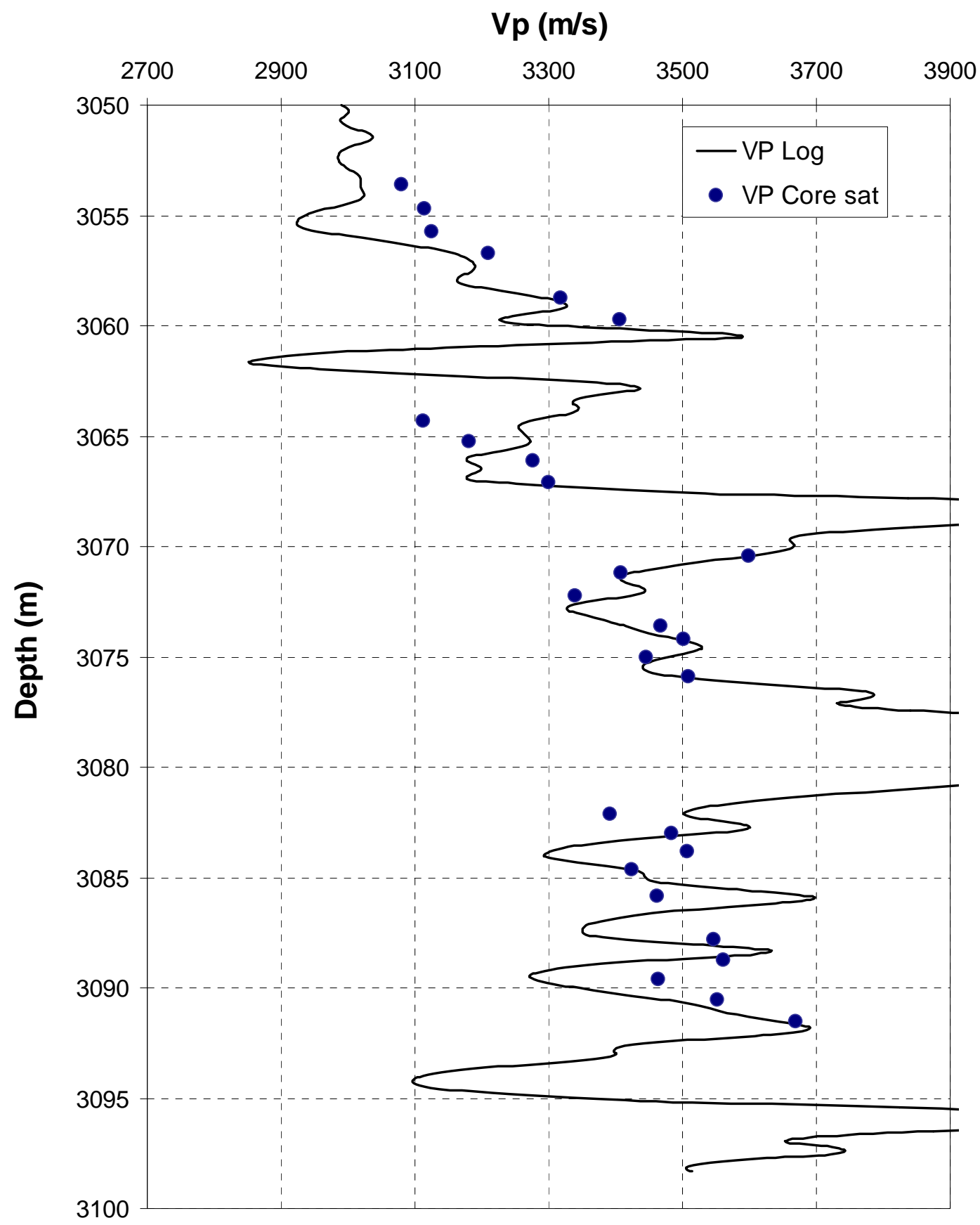

Figure 8. Comparison of saturated P wave velocities computed using Gassmann equation from dry core measurements (dots) against sonic log (line). 


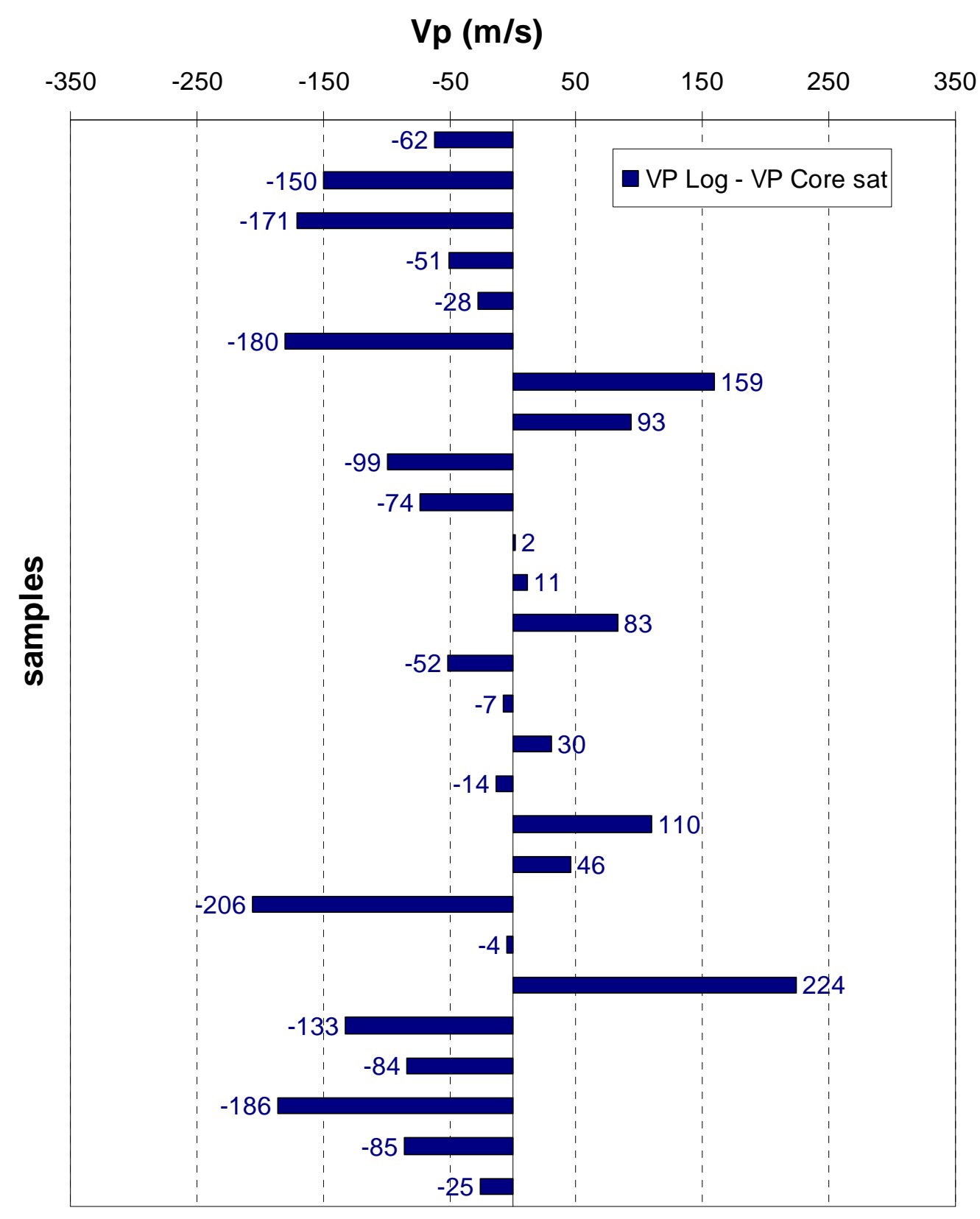

Figure 9. Differences between saturated P wave velocities computed using Gassmann equation from dry core measurements and sonic log. We can see that differences are predominantly smaller than $200 \mathrm{~m} / \mathrm{s}$. 


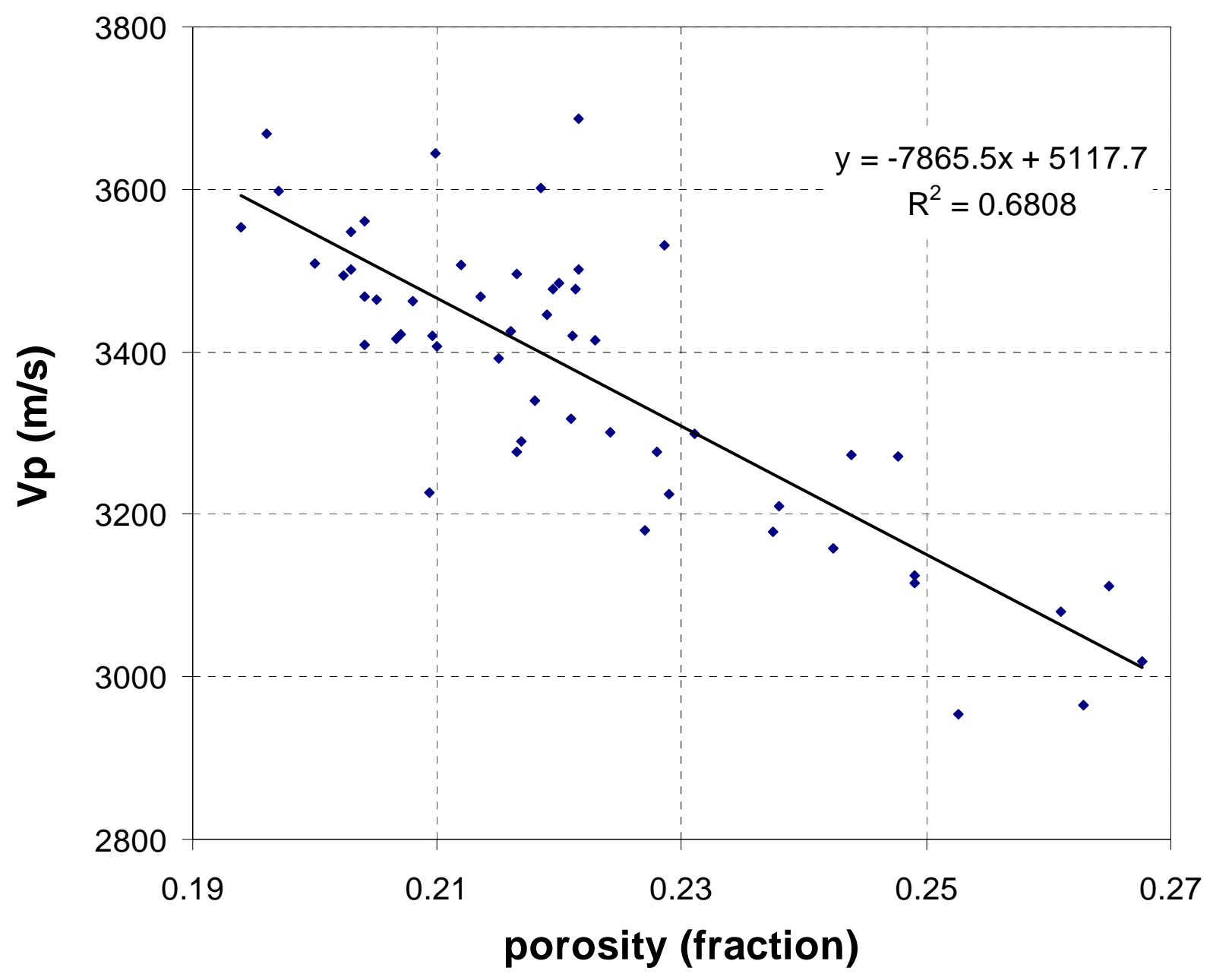

Figure 10. Relationship between porosity and saturated P-wave velocities computed using Gassmann equations. 


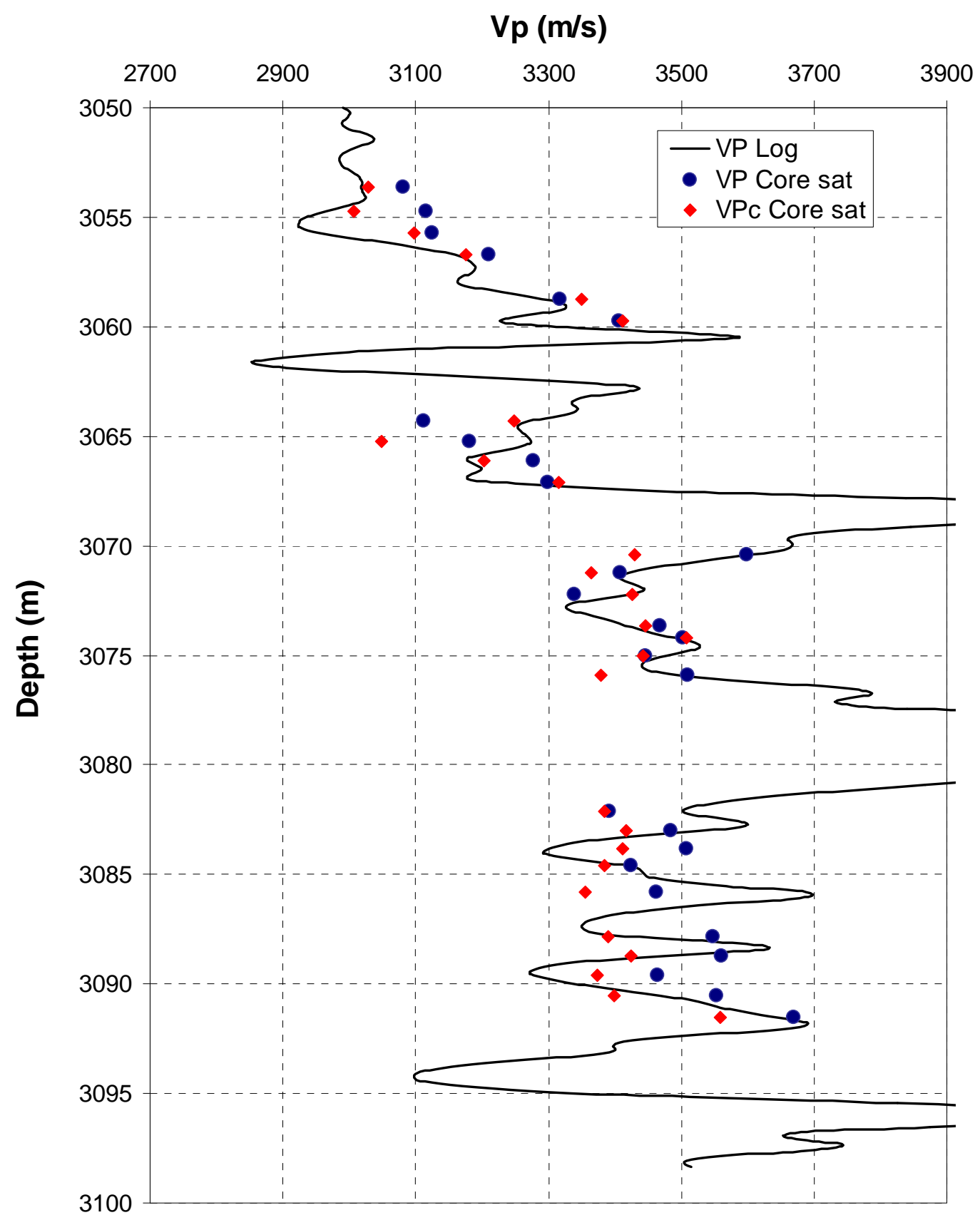

Figure 11. Comparison of saturated P wave velocities computed using Gassmann equation from dry core measurements before (blue dots) and after (red diamonds) porosity correction against sonic log (line). We can see that scale effect correction slightly improves the similarity with log. 


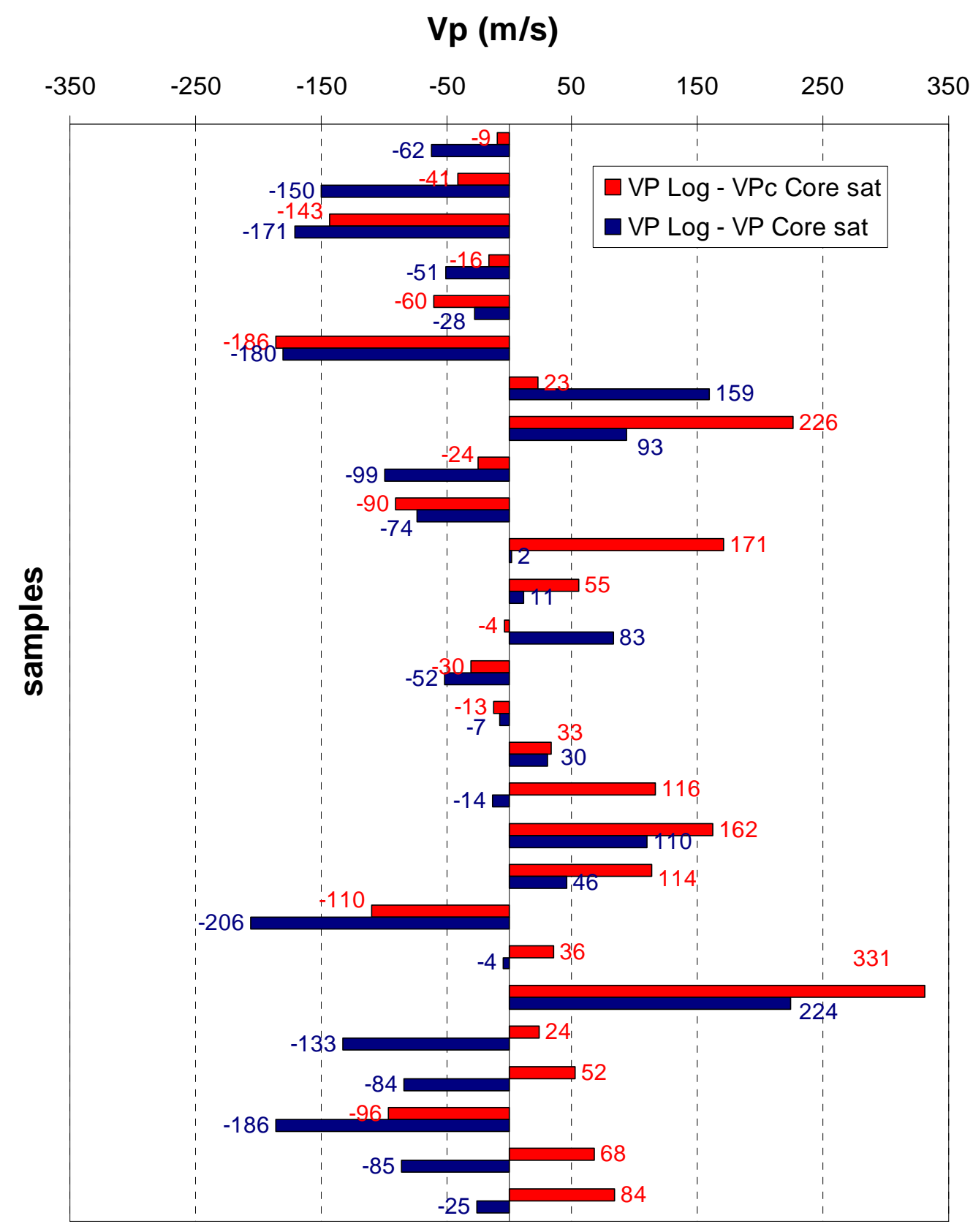

Figure 12. Differences between saturated P wave velocities computed using Gassmann equation from dry core measurements before (blue) and after (red) scale effect correction .and sonic log. We can see that both differences are predominantly smaller than $200 \mathrm{~m} / \mathrm{s}$. 